\title{
O periódico no campo da biblioteconomia no Brasil: possibilidades para um fazer historiográfico
}

\author{
Library science journals in Brazil: \\ a means for historiography
}

Cesar Augusto CASTRO ${ }^{1}$

RESUM O

Debate em torno da imprensa periódica em biblioteconomia como uma das possibilidades de identificarmos sua movimentação enquanto campo do conhecimento. Analisa-se a origem das revistas e a finalidade pelas quais circulam. Privilegia-se as publicações anteriores a década de 70, como: o Boletim Informativo da Federação Brasileira de Associação de Bibliotecários, o Boletim Informativo do Instituto Brasileiro de Bibliografia e Documentação e o Instituto Brasileiro de Bibliografia e Documentação: Notícias Diversas.

Palavras-chave: biblioteconomia-imprensa periódica; historia da Biblioteconomia-Brasil; publicações periódicas.

\begin{abstract}
A B S TR A C T
Discussion about the periodic press in Library Science as a means of identifying its circulation as a field of knowledge, and the origin of magazines and the reason for their circulation is analyzed. Publications released before the 1970s are prioritized, such as: the 'Boletim Informativo da Federação Brasileira de Associação de Bibliotecários', the 'Boletim Informativo do Instituto Brasileiro de Bibliografia e Documentação' and the 'Instituto Brasileiro de Bibliografia e Documentação': Assorted News.
\end{abstract}

Key words: Library Science, periodical press; history of library science, Brazil; periodic press.

I N T R O D U Ç Ã O

O estudo da imprensa periódica, em qualquer campo, constitui-se imperativo para conhecimento da sua movimentação, suas idéias dominantes em determinados períodos e quais os autores mais produtivos, dentre outros aspectos possíveis de investigação. Estas possibilidades investigativas, de acordo com os aspectos de interesse do pesquisador, podem assumir diferentes características e, conse- qüentemente, exigem métodos diversificados, que podem enveredar pela matriz quantitativa, tais como: os estudos de usuários; a avaliação de coleção (VALOIS, 1989, p.30); ou os qualitativos que tratam de conteúdo, identificam fontes de pesquisa, os autores mais produtivos e os temas mais representativos em épocas históricas determinadas. E podem tomar como objeto de estudo os periódicos correntes e retrospectivos (HERSCHAN, 1970; MEADOWS, 1979). Todavia, este separativismo, entre estas duas

\footnotetext{
1 Professor Doutor, Departamento de Biblioteconomia e do Programa de Pós-Graduação em Educação, Universidade Federal do Maranhão. Av. dos Portugueses, s/n, Departamento de Biblioteconomia, Campus Universitário do Bacanga, Bacanga, 65080-021, São Luís, MA, Brasil. E-mail: <ccampin@terra.com.br>.

Recebido em 14/4/2005 e aceito para publicação em 1/9/2005.
} 
abordagens, não assume menor significado atualmente, na medida em que ambas se completam, configurando o paradigma emer-gente de pesquisa como quer Souza, B. (1995).

Face à trajetória acidentada de imprensa periódica no Brasil (LEMOS, 1982), é difícil detalharmos, com profundidade, os aspectos históricos dos mesmos. Os estudos existentes procuram analisar títulos isolados, dificultando, em outra instância, a construção historiográfica de um determinado campo de saber, posto que os mesmos são "lacunares, parcelares e residuais" (NUNES; CARVALHO, 1985). Ziman (1970), ao evidenciar as funções da "mais importante forma de comunicação científica", afirma que, de modo geral, a imprensa periódica apresenta três características que a distinguem de outras fontes impressas:

a) registro público de conhecimento: os periódicos são um meio de registro e preservação dos conhecimentos adquiridos pelo homem (SUBRAMANYAM, 1975), ou seja, desenvolvem funções arquivísticas, armazenando informações sobre pesquisas realizadas. Essa função possibilita estudos sobre os aspectos históricos, filosóficos e ideológicos de um dado campo do saber.

b) função social: o periódico é uma instituição social que confere prestígio e reconhecimento aos autores, editores e comissão que julga os artigos e até aos próprios assinantes (MEADOWS, 1979, p.108). Artigos publicados em periódicos científicos constituem uma medida tangível da contribuição de um autor para o avanço da ciência e base para avaliação de seu trabalho pela comunidade científica. A publicação de resultados facilita o estabelecimento de periodicidades, descobertas e idéias.

c) disseminador de informações. Embora a função de registro público de conhecimento tenha subsistido como única, até metade do século XIX, com o correr do tempo e com o aumento do número de pesquisadores, que passaram a depender deste tipo de publicação como meio de obter informações das atividades desenvolvidas pela comunidade científica de sua área de especialização (MEADOWS, 1979), o periódico alcançou uma nova dimensão e atualmente "[...] muitos deles divulgam informações variadas, que vão desde as comerciais e publicitárias, técnicas e pesquisas, até resenhas e recensões". (CAMPOS; CAMPELO, 1988, p.39).
Neste sentido, Vilhena e Catani (1992, p.1) lembram que "a própria falta de divulgação sobre a localização dos materiais, [dispersão dos mesmos, divulgação deficiente e a diversidade dos círculos de origem] torna ainda mais atomizado e fragmentado o processo" de pesquisa. Tais problemáticas dificultam a precisão do número de periódicos que foram ou estão sendo editados em uma determinada área, por exemplo, Biblioteconomia, constituindo a Imprensa Periódica Biblioteconômica.

Raras são as exceções em que o pesquisador tem o privilégio de dispor em suas análises do "ciclo de vida" das publicações em sua completude, implicando significativamente na dimensão dos resultados da investigação. Este obstáculo não deve ser elemento de desmotivação da pesquisa, contrariamente. Solicita o surgimento de novas fontes que proporcionem a interpretação das lacunas e possibilitem a continuidade da construção histórica.

Assim, tornam-se relevantes os estudos em torno desse material, na medida em que propõe a organização de repertórios e guias de referência, nos quais a sistematização das informações, acerca das produções elaboradas, por e para professores, bibliotecários e historiadores, seja feita de modo a prestar-se a múltiplas utilizações em trabalhos de vários pesquisadores.

No campo educacional, algumas pesquisas têm sido desenvolvidas com objetivo de formalizar os conhecimentos a partir da produção periódica da área. Catani (1988), sobre a Revista de Ensino, publicada pela Associação Beneficente do Professorado Paulista; Bastos (1994) analisa a Revista do Ensino do Rio Grande do Sul e Gandini (1990) centraliza seu estudo na Revista Brasileira de Estudos Pedagógicos, publicadas pelo Instituto Nacional de Estudos e Pesquisas (INEP). No campo da Biblioteconomia, os estudos centrados na imprensa periódica, normalmente, avaliam coleções e analisam citações, mostrando que poucas pesquisas têm pretensões.

No plano internacional, podemos destacar o trabalho pioneiro de Caspard (1981), na França, Nóvoa (1993), em Portugal e Ragazzini (1986), na Itália,com a ressalva de que estes estudos constituem repertórios bibliográficos sobre a imprensa periódica de educação editada nesses países. Todavia, é preciso considerar que a imprensa é como o lugar de uma 
permanente regulação coletiva. Neste sentido, lembra Nóvoa (1993, p.xxxiii) que: "O futuro de um periódico agrega sempre a detalhes e discussões, a polêmicas e conflitos; mesmo quando é fruto de uma vontade individual. A controvérsia não deixa de estar presente no diálogo com os leitores, nas reivindicações junto aos poderes públicos ou nos editoriais de abertura."

Cabe destacar que foram concebidos os materiais da Imprensa Periódica como veículos de comunicação de um dado campo de saber, ou seja, como um mecanismo de divulgação de suas atividades. Isso possibilitou ao pesquisador compreender a sua trajetória, suas idéias dominantes em determinado período, suas principais lideranças, dentre outros aspectos possíveis face à riqueza de contribuições discursivas advindas deste tipo de material. Nesse sentido Nóvoa (1993) afirma que a imprensa é, talvez, o melhor meio para compreender as dificuldades de articulação entre a teoria e a prática: o senso comum, que perpassa as páginas dos jornais e das revistas, ilustra uma das qualidades de um discurso biblioteconômico que se contrai a partir dos diversos autores em presença.

\section{A Imprensa Periódica Biblioteconômica}

Neste artigo foi enfocada a análise da Imprensa Periódica Biblioteconômica produzida por diversas instâncias, no período dos anos 50 e 60. Por não haver um repertório no qual pudesse se localizar a produção das Associações de Classe, Escolas e Cursos, centralizou-se as buscas na Bibliografia Brasileira de Biblioteconomia, publicada em 1959 por Oswaldo de Carvalho, na Bibliografia de Documentação: 1960/1970, Bibliografia Brasileira de Documentação (1960); e ainda nas bibliografias inseridas na Revista do Livro, editada pelo Instituto Nacional do Livro, e no livro A Biblioteconomia Brasileira de Laura Russo.

Outras publicações são editadas por Associações de Classe: BAMBI (1959), pela Associação de Bibliotecários de São Paulo; Notícias de ABB (1952) e Bibliotecas e Bibliotecários (1957), pela Associação de Bibliotecários Brasileiros; Boletim Informativo da FEBAB (1960), pela Federação Brasileira de Associação de Bibliotecários; Boletim $I B B D$, pelo Instituto Brasileiro de Bibliografia e Documentação atual, Instituto Brasileiro de Informação em Ciência e Tecnologia e Boletim ABDF (1966) pela Associação dos Bibliotecários de Brasília.

Ao referir-se às publicações periódicas na Biblioteconomia, anteriores a 1970, Fonseca (1957), afirma que:

Há poucas revistas especializadas em Biblioteconomia no Brasil. Quanto a Imprensas pode-se citar duas: O Boletim Bibliográfico de Mário de Andrade [...] e o Boletim Informativo do Instituto Brasileiro de Bibliografia e Documentação. A primeira é anual e a segunda é bimestral. A Biblioteca do Departamento Administrativo do Serviço Público - DASP edita, desde 1944, uma pequena revista impressa em multilith, com periodicidade irregular.

A denominação atribuída por este autor Revistas - contrapõe-se à afirmação de Souza, F. (1995) e Miranda (1981), quando declaram que estas se iniciaram na década de 70. Ciência da Informação, criada em 1972 pelo IBBD, com a finalidade de ser um veículo de "divulgação e desenvolvimento das principais atividades do setor de informação cientifica e tecnológica" (EDITORIAL, 1972, p.1). Em 1973, a Associação de Bibliotecários do Distrito Federal (ABDF), com a colaboração do Curso de Biblioteconomia da Universidade de Brasília (UnB), lança a Revista de Biblioteconomia de Brasília, com a finalidade de ser "um veículo de comunicação de idéias, experiências e realizações da comunidade biblioteconômica brasileira" (EDITORIAL, 1973, p.2). A Revista da Escola de Biblioteconomia da Universidade Federal de Minas Gerais (UFMG) começou a circular no mesmo ano da Ciência da Informação destinava-se à publicação de trabalhos, que contribuíssem para o desenvolvimento da Biblioteconomia e Documentação no Brasil e que tratasse de assuntos ligados a estes dois campos (EDITORIAL, 1972, p.2). Neste sentido, segundo Neves e Melo (1983, p.22):

A partir da década de 70 é que surgem, no Brasil, as revistas de maior relevância, nas áreas de Biblioteconomia e Documentação, o que demonstra a tomada de consciência dos profissionais no que concerne à necessidade da libertação da Bibliografia importada. Por outro lado, é índice de autonomia nas pesquisas e de adaptação dos problemas às características nacionais, em busca de induções mais condizentes com a realidade brasileira. 
A FEBAB, desde 1960, editava o Boletim Informativo, e em 1973, em substituição ao Boletim, passou a publicar trimestralmente a Revista Brasileira de Biblioteconomia e Documentação. Em principio o seu objetivo era documentar a legislação bibliotecária e correlata. Mas a partir de 1978 inaugura uma nova fase, com periodicidade semestral, voltando sua atenção "as matérias que tratem de temas técnicos, científicos e educacionais da Biblioteconomia e Documentação" (EDITORIAL, 1978, p.1). As escolas de Biblioteconomia de Pernambuco e da Bahia lançam, nos anos 80 , os seus Cadernos de Biblioteconomia, ambas de vida efêmera.

A proliferação da imprensa Periódica Biblioteconômica, a partir da década de 70, ocorreu devido à duas situações. A primeira, pelo crescimento dos cursos de pós-graduação; e a segunda, pelo alerta de Hipólito Escobar, quando esteve no Brasil, em 1968, em missão da Organização das Nações Unidas para Educação, Ciência e Cultura (UNESCO), ao considerar a ausência de periódicos como um dos dez pontos negativos da Biblioteconomia brasileira.

Inicialmente, estas revistas atendiam a determinados interesses da profissão: "[...] a Revista da Escola de Biblioteconomia da UFMG veicula artigos sobre Ensino de Biblioteconomia" (MIRANDA, 1981, p.31), trazendo para este assunto contribuições significativas. Acreditamos que alguns avanços ocorridos no ensino devam-se a esta publicação. A Revista de Biblioteconomia de Brasília sobre Sistemas de Informação e Disseminação Seletiva da Informação. ARevista Ciência da Informação, sobre pesquisas centradas no método bibliométrico como reflexo da experiência de grupos de pesquisadores ingleses e norte-americanos, que estiveram ministrando cursos e orientando os primeiros mestres em Ciência da Informação no Brasil. Enfim, estas revistas demonstram, nesta fase, uma tendência dos cursos de pós-graduação de Minas Gerais, Rio de Janeiro e Brasília. Inclusive, Brasília destacou-se alguns anos na área, chegando a ser considerada a "Capital da Biblioteconomia". Esta denominação se dá, ao meu ver, mais pela emergência do mercado de trabalho do que pela quantidade de publicações.
A centralização em determinadas temáticas da Biblioteconomia "em vez de constituir-se, portanto, em uma 'política editorial' consciente, tratar-se-ia mais bem uma tendência que pode ou não ter continuidade" (MIRANDA, 1981, p.31). Atualmente, observa-se que as publicações citadas têm a mesma identidade e interesse, sendo difícil distinguirmos a linha editorial das mesmas. No entanto, supõe-se que seja a questão relacionada à gestão de políticas de informação e tecnologias de informação. Todavia, assuntos relacionados ao ensino, a leitura, a história, aos serviços técnicos de organização e recuperação de informação, são pouco representativos quando comparados aos anteriores. Tal fato demonstra que o campo da Biblioteconomia e Ciência da Informação tem avançado em termos teóricos e metodológicos em algumas temáticas. No entanto, essas temáticas não surgiram por um aspecto natural, mas, sim, pela decorrência de escolhas sócio-históricas. A crítica feita neste trabalho é o fato de que ao "abandonar" outras possibilidades de interpretação e compreensão das práticas e dos saberes biblioteconômicos, como as citadas, pode-se cristalizar a dinâmica da produção científica da área.

Considera-se Transinformação, revista publicada pelo programa de pós-graduação em Ciência da Informação da Pontifícia Universidade Católica de Campinas, a mais eclética, na medida em que procura publicar temas variados, o que minimiza a crítica acima. Contudo, devido ao pequeno número de publicações na área e pela irregularidade das mesmas, a "centralidade temática" pode levar a circularidade da produção da área.

Por sua vez, Biblioteca e Sociedade, editada pelo Curso de Biblioteconomia em Biblioteconomia da Universidade Federal da Paraíba, procura firmar-se nesse oceano de indecisões editoriais. No momento, este periódico, e certamente os demais, procuram contornar as dificuldades financeiras que os impedem de circular com regularidade.

As revistas eletrônicas, que não entram em discussão neste texto, surgem como uma das formas encontradas pelas instituições para sanar e/ou ampliar a produção e circulação dos sabes biblioteconômicos, a exemplo da Datagramazero, Encontros Bibli, bibli.fae, dentre outros ${ }^{2}$.

\footnotetext{
2 Lista completa das publicações brasileiras e internacionais do campo de Biblioteconomia e Ciência da Informação pode ser consultada em <www.abecin.gov.br>.
} 
Uma questão que cabe ser feita é se a centralidade das temáticas retrata a instabilidade teórica da Biblioteconomia e Ciência da Informação, ou ao contrário, o campo está movimentando-se positivamente na teoria e na prática as revistas publicam "assuntos da moda", como foram reengenharia, qualidade total da informação, dentre outros?

Como o interesse, neste texto, corresponde as duas décadas anteriores aos anos 70 , selecionamos o Boletim Informativo da FEBAB, o Boletim Informativo do IBBD e o IBBD - Notícias Diversas, sendo estes últimos prolongamentos do primeiro. $A$ escolha destas fontes deu-se por duplo objetivo. $\mathrm{O}$ primeiro de firmar a idéia de que a imprensa periódica biblioteconômica não começou na década de 70 e, a segunda, de que ao resgatar outras materialidades documentais pode-se contribuir para (re)conduzir um debate em torno da necessidade de estudos e pesquisas, que procurem emergir os aspectos historiográficos da biblioteconomia brasileira.

\section{Boletim Informativo da Federação Brasileira de Associação de Bibliotecários - FEBAB}

Esta instituição, como o nome indica, congrega todas as associações de classe bibliotecárias brasileiras; logo, esta fonte, hipoteticamente, representa o pensamento da categoria, daí a sua incorporação na pesquisa, além de apresentar periodicidade regular. O Boletim Informativo da FEBAB começou a circular em 1960, com a finalidade de: "[...] contribuir para o progresso da Biblioteconomia no Brasil: 1) orientando os bibliotecários para a apreciação de novas técnicas e processos; 2) tornando conhecidos, no seio da classe, as reivindicações profissionais; 3 ) publicando notícias das atividades das Escolas e Associações de Bibliotecários". (FEDERAÇÃO..., 1960, p.1).

Sendo assim, esta fonte procura retratar a importância desta Federação, enquanto espaços legítimos da categoria, sustentando que, a partir dela e com ela, as reivindicações profissionais seriam atingidas, na medida em que todos unissem suas forças e necessidades em torno de uma Biblioteconomia reconhecida, enquanto profissão liberal e de nível superior, dotada de um currículo único e incorporada ao espaço universitário.

$\mathrm{Na}$ apresentação do v.5, n.1/2, de 1962, problemas relacionados ao ensino de Biblioteconomia assumem destaque, sendo publicados diversos dispositivos legais, como a proposta de manter os professores e bibliotecários atualizados a respeito das mudanças que se processavam neste campo, mesmo com a aprovação do currículo mínimo de 1962 e reconhecimento da profissão como de nível superior. Matérias desta natureza seriam editadas até 1968 , demonstrando a luta pela conquista educacional da Biblioteconomia, em especial, da necessidade de sua expansão. Portanto:

\begin{abstract}
Este boletim foi formulado dentro de um plano sistemático, nas linhas gerais, e flexível nos aspectos particulares. Este boletim tem procurado oferecer uma visão imediata dos problemas de ensino, das dificuldades com que se defrontam os profissionais responsáveis pelo desenvolvimento da biblioteconomia no Brasil. (BOLETIM..., 1961, p.2).
\end{abstract}

Ainda neste sentido, a publicação pretendia "[...] oferecer facilidades de acesso à matéria de interesse das Escolas de Biblioteconomia e de todos aqueles que se interessam pelos assuntos da Educação." (BOLETIM..., 1961, p.2).

A divulgação das atividades científicas desenvolvidas no país e estrangeiro, no campo da Biblioteconomia e Documentação, os trabalhos das Comissões Nacionais, (Catalogação e Classificação) e notícias de interesse dos bibliotecários ocupam parte significativa da publicação, possibilitando a identificação dos movimentos ocorridos na década de 60. Evidentemente, dependendo das reivindica-ções profissionais, uma mesma temática estende-se por vários números ou anos.

De 1968 até 1970, a sua circulação é subvencionada pelo Instituto Nacional do Livro, quando é substituído, em 1970, pela Revista Brasileira de Biblioteconomia e Documentação.

\section{Boletim Informativo do Instituto Brasileiro de Bibliografia e Documentação}

Por ser uma publicação do mais importante órgão de informação e documentação, na época, 
foi criado para "[...] promover o intercâmbio de informações entre as instituições de pesquisa, no Brasil e no estrangeiro, dos trabalhos técnico-científicos brasileiros". (SAMBAQUY, 1955, p.1) .

Dá destaque, então, às diversas facetas da ciência, podendo-se encontrar desde artigos sobre Física Nuclear até Geografia. Porém, os artigos sobre Biblioteconomia e Documentação ocupam maior espaço e é onde se evidencia o papel do profissional bibliotecário e das bibliotecas, diante o avanço das pesquisas no Brasil.

O IBBD, para concretizar sua finalidade, publica "[...] bibliografias especializadas correntes, guias das instituições de pesquisa brasileira e de suas bibliotecas, o Boletim do Conselho Nacional de Pesquisa, editados, de preferência, em português e inglês." (SAMBAQUY, 1955, p.1) ${ }^{3}$.

Assim, este Boletim pretendia "[...] dar notícias atuais e de interesse para a pesquisa bibliográfica registrando o que se passa no mundo científico e tecnológico brasileiro, principalmente o que estiver relacionado com os trabalhos do Conselho Nacional de Pesquisa e Instituições que lhe são relacionados." (SAMBAQUY, 1955, p.2).

Estas informações contidas no artigo "A Razão de ser deste Boletim", assinado por Lídia de Queiroz Sambaquy, alerta aos leitores que, na sua fase inicial, seria falho e incompleto, mas, vencidas as primeiras dificuldades, poderia "[...] servir como primeiro veículo para o contato permanente que cabe a este instituto criar e manter entre as instituições nacionais e estrangeiras". (SAMBAQUY, 1955, p.2).

Em todos os artigos publicados, manifesta-se a idéia segundo a qual o bibliotecário seria aquele que atenderia aos anseios da ciência. Logo, deveria conhecer as terminologias das áreas em que atuava. Desta forma, obteria status e respeito profissional junto à comunidade científica e à sociedade em geral, discurso que encontra ressonância nos cientistas defensores da categoria, como Paulo Sawaya (1957). Daí a insígnia encontrada em todos os trabalhos publicados neste periódico que tratam do bibliotecário
Para corresponder a esta necessidade científica, foram promovidos diversos cursos de especialização, ministrados por bibliotecários que tratavam dos conteúdos específicos e por cientistas, que introduziam conhecimentos das Ciências Físicas e Naturais, Ciências Médicas e Tecnológicas.

A partir de 1961, ao mudar de nome para IBBD: Notícias Diversas centra-se na Biblioteconomia e na Documentação. Nesta fase, a periodicidade é bastante irregular. Em 1967, ocorre uma nova mudança no título, agora IBBD: Notícias, mas a linha editorial permanece até 1973, quando cessa de circular.

Acreditamos, que a imprensa periódica traz uma ampla possibilidade para a reconstituição da história da biblioteconomia, que podem revelar que as reivindicações dos profissionais atuais continuam as mesmas, revestidas, entretanto, de outras roupagens, que nos parecem, totalmente novas: mercado emergente de trabalho; relação ensino e sociedade, estratégias para divulgar a profissão e o profissional, impacto das novas tecnologias no processo de organização, tratamento e recuperação da informação, da história da Catalogação e da Classificação, das bibliotecas, do livro e das práticas de leituras, do movimento associativo e inúmeras outras temáticas que poderão explicar melhor e mais amplamente a constituição deste campo.

A história das disciplinas escolares poderia levar a concluir que o que era uma unidade de determinada disciplina, desde os anos 20, passou a constituir uma nova. Em termos de saberes escolares, alterações deram-se pela necessidade de adaptar o currículo escolar as novas determinações sociais, culturais, científicas e tecnológicas.

Em resumo, a Imprensa Periódica Biblioteconômica pode ser uma possibilidade para tecer-se a história da biblioteconomia brasileira em todas as suas possibilidades e determinações, como a educacional, tecnológica, técnica, etc. Deste modo, acredita-se que esta área pode ser (re)pensada, assim como a formação dos profissionais que dela se ocupam.

3 A autora assina os artigos que publica nesta publicação, com a abreviatura L.Q.S. 
BAMBI. São Paulo: Associação de Bibliotecários Municipais de São Paulo, 1959.

BASTOS, M.H.C. O novo e o nacional em revista: a revista do ensino do Rio Grande do Sul - 1939 - 1942. 1994. Tese (Doutorado em Educação) - Universidade de São Paulo, São Paulo, 1994.

BIBLIOGRAFIA BRASILEIRADE DOCUMENTAÇÃO. Rio de Janeiro: IBBD, 1960.

BIBLIOTECAS e bibliotercários. Rio de Janeiro: Associação Brasileira de Bibliotecários, 1957.

BOLETIMABDF. Brasília:Associação de Bibliotecários do Distrito Federal, 1966.

BOLETIM Informativo FEBAB, v.5, n.1, p. 2-10, 1961.

CAMPOS, C.M.; CAMPELO, B.S. Fontes de informação especializada. Belo Horizonte: UFMG, 1988.

CASPARD, P. Le presse d'éducaton et d'enseignement. Paris: CNRS, 1981.

CATANI, D. Educadores à meia-luz. 1998. Tese (Doutorado em Educação) - Universidade de São Paulo, São Paulo, 1988.

EDITORIAL. Ciência da Informação, Rio de Janeiro, v.1, n.1, p.1, 1972.

EDITORIAL. Revista Ciência da Informação e Biblioteconomia, Brasília, v.1, n.1, p.1, 1973.

EDITORIAL. Revista de Biblioteconomia e Documentação, São Paulo, v.1, n.1, p.1, 1978.

FEDERAÇÃO BRASILEIRA DE ASSOCIAÇÃO DE BIBLIOTECÁRIOS. Boletim Informativo da FEBAB. São Paulo: FEBAB, 1960. p.1.

FONSECA, E.N.F. Desenvolvimento da Biblioteconomia e da Bibliografia no Brasil. Revista do Livro, v.2, n.5, p.95120, 1957.

GANDINI, R.P.C. Revista Brasileira de Estudos Pedagógicos (1944-1953): intelectuais, educação e estudo. 1990. Tese (Doutorado em Educação) - Universidade Estadual de Campinas, Campinas, 1990.

HERSCHAN, A. The primary journal: past, present and future. Journal of Chemical Documentation, v.10, n.1, p.23-38, 1970.
LEMOS, A.A.B. As revistas brasileiras no setor de saúde. Comunicação e Sociedade, v.4, n.7, p.86, 1982.

NEVES, C.S.; MELLO, D. Biblioteconomia: legislação. In: ENSINO Superior no Brasil: legislação e jurisprudência. Rio de Janeiro: MEC, 702p.

NOTÍCIAS da ABB. Rio de Janeiro: Associação Brasileira de Bibliotecários. 1952.

MEADOWS, A.J. The scientific journal. Londres: ASLIB, 1979.

MIRANDA, A. Revistas especializadas em Biblioteconomia e Ciência da Informação. Boletim ABDF: Nova Série, v.4, n.4, p.31, 1981.

NÓVOA, A. A imprensa de educação e ensino. Lisboa: Instituto de Inovação Intelectual. 1993. p.xxxiii.

NUNES, C.; CARVALHO, M.M.C. Historiografia da educação e fontes. Cadernos ANPED, Porto Alegre, n.5, p.57-64, 1985.

RAGAZZINI, D. Repertório bibliográfico di storia dell' educazionne. Firenze: Sansoni Editore Nuova, 1986.

SAMBAQUY, L.Q. A razão de ser deste Boletim. Boletim IBBD, v.1, n.1, p.1-2, 1955.

SAWAYA, P. Contribuição da Biblioteconomia para o trabalho cientifico. IBBD: Boletim Informativo, v.3, n.3/4, p.143-152, 1957.

SOUZA, B. Um discurso sobre as ciências. Lisboa:Apontamento, 1995.

SOUZA, F. Modernização e Biblioteconomia nova no Brasil. Piracicaba, 1995. Tese (Doutorado em Educação) - Universidade Metodista de Piracicaba, Piracicaba, 1995.

SUBRAMANYAM, K. La revista científica: estudio de las tendencias actuales y las perspectivas futuras. Bol. Bibl. de la UNESCO, v.4, n.106, 1975.

VALOIS, E.C. et al. Comunicação científica e usuários: elementos de discussão. Ciência da Informação, Brasília, v.18. n.1, p.30, 1989.

VILHENA, C.P.S., CATANI, D.B. A imprensa periódica educacional e as fontes para a história da cultura escolar brasileira. Texto apresentado na XV Reunião Anual daANPED, Caxambu, Minas Gerais, set. 1992. mimeo.

ZIMAN, J. Conhecimento público. São Paulo: Itatiaia, 1970. 
